\title{
The Meteorite of April 25, 1969
}

by

\section{A. D. ANDREWS \\ Armagh Observatory \\ T. W. RACKHAM \\ Armagh Planetarium \\ P. A. WAYMAN \\ Dunsink Observatory}

A meteonitic body entered the Earth's atmosphere somewhere over the south of England on April 25, 1969, and at 2021 U'T was seen by thousands of people in most parts of the British Isles to be travelling on a nearly level path in a north-westerly direction. It was reported from places as far separated as London, Cork and Malin Head. A clear view was obtained from many parts of Ireland and a large number of sightings have been reported to Dunsink Observatory, Armagh Observatory and Planetarium, and to Mr Terence Murtagh of the Belfast Centro of the Irish Astronomical Society, who requested such reports.

Observations from England have now been satisfactorily combined with the Irish observations to give a reasonably accurate path, but before this had been done authentic fragments of the meteorite were recovered from a Royal Ulster Constabulary building in Lisburn, Co. Antrim, where they had penetrated an asbestos roof, and from a farm near Kilrea, Co. Londonderry, where a $7 \mathrm{~kg}$ picee was picked up near to farm buildings. A line

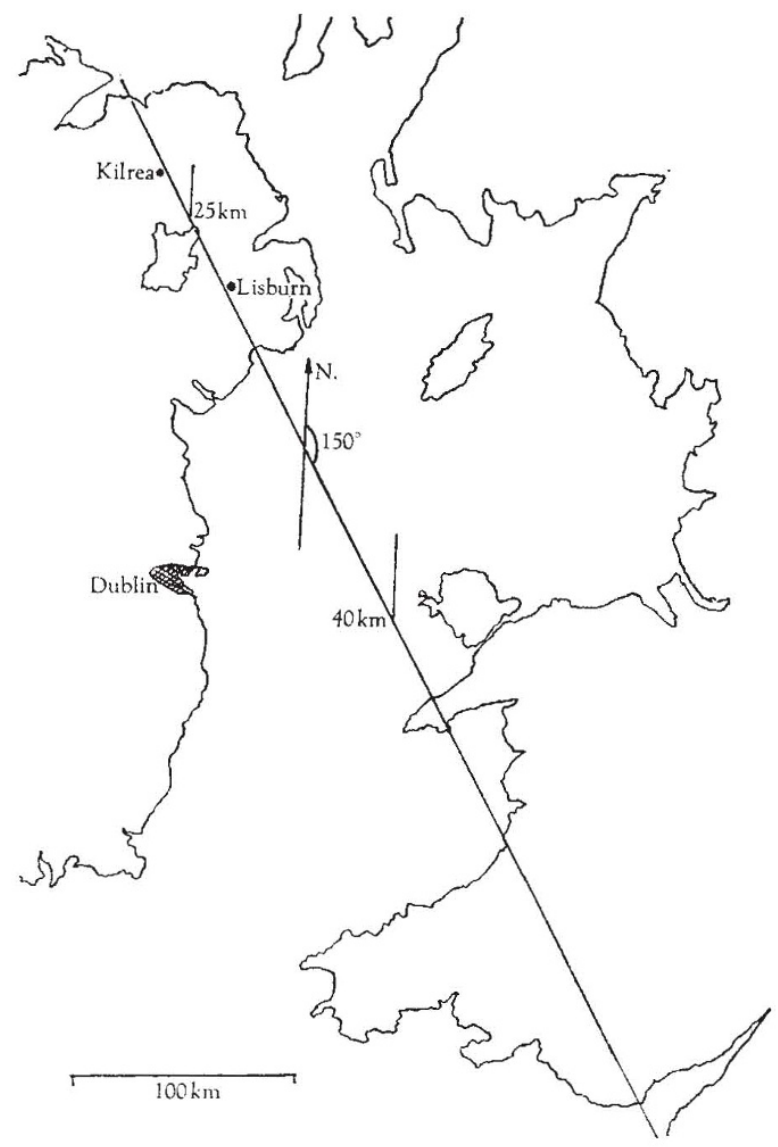

Fig. 1. 'The track of the meteorite from S. Wales to N. Ireland. Heights are indicated by two vertical lines of appropriate length. joining these two places, which are separated by $52 \mathrm{~km}$, passes over Anglesey and crosses the Irish coast near Ardglass, and at both these places the meteorite was reported as passing overhead. The altitudes recorded at Dublin and at Keele (communicated by Dr R. C. Maddison), however, seem to indicate that the path was not quite on this line and the path shown in Fig. 1 has been deduced on the assumption that it must pass near Kilrea and Lisburn and must fit about fifteen sets of altitude and azimuth estimates from Armagh, Dundalk, Dublin, Navan, Keele, London, Garron Point, Malin Head, Dunboyne and Newtownhamilton. "Overhead" is often interpreted as "within $25^{\circ}$ or $30^{\circ}$ of the zenith" and the Ardglass and Anglesey observations are consistent with the deduced heights along this path of $40 \mathrm{kmn}$ near Anglesey and $25 \mathrm{~km}$ over Lough Neagh.

The bolide was clearly seen to break up into, first, three and then more pieces approximately over the Co. Down coast. Observations of the end point are, as is usual when the path is nearly level, not mutually consistent, but it seems that the largest fragments probably fell into the Atlantic Ocean near Malin Head. The angle of the path to the horizontal over Ireland was only about $4^{\circ}$ and the observed path was more than $600 \mathrm{~km}$ long. The time taken to travel this path was about $20 \mathrm{~s}$. The brightness of the fireball as seen from Dublin was probably slightly in excess of the full Moon. It came at a time when daylight in Ireland had not quite faded and the illumination was widely noticed from inside illuminated uncurtained rooms. According to a personal estimate (P. A. W.) the apparent size of the bright region around the head of the fireball was $10 \mathrm{~min}$ of arc, which, at a distance of $80 \mathrm{~km}$, indicates a diameter of just over $200 \mathrm{~m}$. The pre. sence of a tail, probably extending $5^{\circ}$ or more behind the nucleus, was noted by practically all observers, as were the characteristic flashes of differing hues and the apparent seattering away of small parts as "sparks". The sonic shockwave was heard in Dublin 3.5 min after the visual sighting and in Armagh (45 km from the track) after about $1.5 \mathrm{~min}$, but the estimates for this interval are very diverse. Some observers in the Dublin area and in Northern Ireland reported a simultaneous "swishing" noise, which has often been reported on past occasions and which is now believed to be a real physical phenomenon of obscure cause, possibly associated with ionizing radiation.

The large fragment at Kilrea and part of the Lisburn piece have been dispatched via Queen's University, Belfast, Armagh Observatory and Dr Gale, University of Oxford, to AERE, Harwell, and to the Centre of Weak Radioactivity, Paris, for radioactive analysis. All other suspected fragments have, as far as we know, not bren confirmed as meteoritic, but on the farm where the large fragment fell a heap of (apparently) ablation fragments (characteristic size $0.5-3 \mathrm{~mm}$ ) was discovered, some of which are noticeably "magnetic" and others less so. These particles may be of considerable interest.

We thank Dr R. C. Maddison of Keele and Dr S. Cauley of Dublin for passing on their observations, and $\mathrm{Mr} \mathrm{C}$. $J$. Butler for assistance. Received May 15, 1969. 